\title{
Blind Deconvolution Algorithms for MIMO-FIR Systems Driven by Fourth-order
}

\section{Colored Signals}

\author{
Mitsuru Kawamoto', Yujiro Inouye ${ }^{2}$, \\ Department of Electronic and Control Systems, \\ Shimane University, \\ 1060 Nishikawatsu, Matsue, Shimane 690-8504, JAPAN \\ 1. kawa@ecs.shimane-u.ac.jp \\ 2. inouye@riko.shimane-u.ac.jp
}

\section{Abstract}

This paper deals with the blind deconvolution problem of MIMO-FIR channels driven by source signals which are temporally second-order uncorrelated but fourth-order correlated and spatially second- and fourth-order uncorrelated. Recently, we proposed a criterion for solving the blind deconvolution problem [8], [9]. However, we have not yet shown an algorithm to implement our proposed criterion. One of our objectives in the present paper is to propose an iterative algorithm for achieving the blind deconvolution by using this criterion. To achieve this objective, we consider an approach called the non-deflation method. We propose an iterative algorithm based on the method. Moreover, we present a deflation algorithm using this criterion for the blind separation of MIMO constant channels.

\section{Introduction}

Blind deconvolution is a problem of extracting source signals from their convolutive mixtures observed by sensors without knowing the source signals along with the transfer function between the sources and the sensors. The blind deconvolution has drawn an attention in diverse fields, for example, digital communications, speech processing, image processing, and array signal processing, etc.

The blind deconvolution problem has been studied by many researchers. For example, see [1]-[4] and references therein. Almost all the methods proposed to date have been developed under the assumption that the source signals are temporally independent and identically distributed (i.i.d.) and spatially independent (e.g., see [2]-[4]). However, there are some applications in which the condition of i.i.d. for the source signals is very strong. For example, in digital communications, the information bearing sequences are coded in order to combat noise corruption and channel distortion. These codes implicitly are not mutually independent among sequences and hence it is unlikely that they are i.i.d. signals. However, these code sequences are interleaved to avoid burst errors when the codes are transmitted [5]. These interleaved sequences are usually considered to be uncorrelated. To solve the blind deconvolution problem for such an application, therefore,

\author{
Ruey-wen $\mathrm{Liu}^{3}$ \\ Department of Electrical Engineering, \\ University of Notre Dame, \\ Notre Dame, IN 46556, USA \\ 3.ruey-wen.liu.1@nd.edu
}

we should take account of an assumption that the source signals have a weaker condition than the i.i.d. condition, for example, the source signals are temporally second-order uncorrelated but high-order correlated.

In this paper, we deal with the blind deconvolution of MIMO-FIR channel systems driven by source signals which are temporally fourth-order colored signals (but temporally second-order white and spatially second- and fourth-order uncorrelated signals). The condition for the source signals is weaker than the i.i.d. condition. We previously proposed a criterion for blind deconvolution under this condition [8], [9]. However, we did not show any algorithms to implement the blind deconvolution using the proposed criterion.

One of our objectives in this paper is to propose an iterative algorithm to solve the blind deconvolution problem by using the proposed criterion. To this end, we consider the non-deflation approach for recovering the source signals simultaneously from their convolutive mixtures. Equalizers of MIMO-FIR channels are used to acquire the function of blind deconvolution. The proposed algorithm iteratively adjusts the parameters of equalizers so that the criterion takes a minimum. We carry out computer simulations using the proposed algorithm. The simulation results show that our algorithm can solve the blind deconvolution problem.

It is well-known that there is an approach called the deflation method for the blind separation of sources under the assumption that the source signals are i.i.d. and spatially independent. However, it is not clear whether the deflation approach can be applied to the MIMO-FIR channels in the case where the sources are fourth-order colored. It is shown in the present paper that this is the case for MIMO constant channels. Namely, we propose a deflation algorithm using this criterion for the blind separation of MIMO constant channels.

\section{Problem formulation}

We consider an MIMO-FIR system given by the following equation:

$$
x(t)=\sum_{k=0}^{K} H^{(k)} s(t-k)
$$


where $\mathbf{x}(\mathrm{t})$ represents an $\mathrm{m}$-column output vector called the observed signal, $\mathbf{s}(\mathrm{t})$ represents an $\mathrm{n}$-column input vector called the source signal, $\left\{\mathrm{H}^{(\mathrm{k})}\right\}$ is an $\mathrm{m} \times \mathrm{n}$ matrix sequence representing the impulse response, and the number $\mathrm{K}$ denotes its order. Equation (1) can be written as

$$
x(t)=H(z) s(t),
$$

where $\mathbf{H}(z)$ is the transfer function, which is defined by the $\mathrm{z}$-transform of the impulse response $\left\{\mathbb{H}^{(\mathrm{k})}\right\}$, that is,

$$
\mathbf{H}(\mathrm{z})=\sum_{\mathrm{k}=0}^{\mathrm{K}} \mathbf{H}^{(\mathrm{k})} \mathrm{z}^{\mathrm{k}} .
$$

One of the objectives in this paper is to work out an iterative algorithm to solve the blind deconvolution problem. To this end, we consider the following FIR system called the equalizer.

$$
y(t)=\sum_{k=0}^{L} W^{(k)} x(t-k),
$$

where $y(t)$ is an $n$-column vector representing the output signal of the equalizer, $\left\{\mathbf{W}^{(k)}\right\}$ is an $n \times m$ matrix sequence, and the number $L$ is the order of the equalizer. Equation (3) can be written as

$$
y(t)=W(z) x(t),
$$

where $W(z)$ is the transfer function of the equalizer defined by

$$
\mathbf{W}(z)=\sum_{k=0}^{L} W^{(k)} z^{k}
$$

Substituting (2) into (4), we have where

$$
y(t)=W(z) H(z) s(t):=G(z) s(t)
$$

$$
G(z):=W(z) H(z)=\sum_{k=0}^{K+L} G^{(k)} z^{k}
$$

Figure 1 shows the cascade system of an unknown system followed by an equalizer.

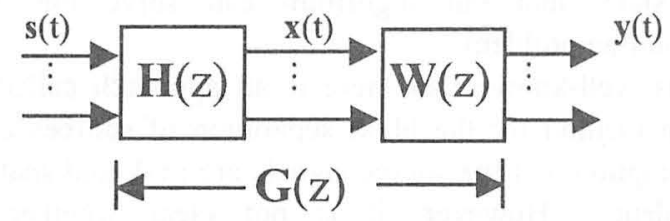

Figure 1 The cascade system of an unknown system and an equalizer.

We allow all the variables to be complex-valued. This is required for such an application using quadrature amplitude modulation (QAM) signals [5]. If $\mathrm{G}(\mathrm{z})$ in (6) becomes a matrix $G_{0}(z)$ of the form defined by

$$
\mathrm{G}_{0}(\mathrm{z})\left(=\mathbf{W}_{0}(\mathrm{z}) \mathrm{H}(\mathrm{z})\right)=\Lambda(\mathrm{z}) \mathbf{D P},
$$

then the each component of $s(t)$ is recovered by some component of $y(t)$, except for three types of ambiguities, that is, the order ambiguity, the time-origin ambiguity, and the magnitude ambiguity, because $\Lambda(z)$ is a diagonal matrix with diagonal elements $\lambda_{\mathrm{ij}}(\mathrm{z})=\mathrm{z}^{l_{\mathrm{i}}} \quad(\mathrm{i}=1, \ldots, \mathrm{n})$ (where $l_{\mathrm{i}}$ is a nonnegative integer), $\mathbf{D}$ is a regular constant diagonal matrix, and $\mathbf{P}$ is a permutation matrix. Hence, the $\mathrm{i}$-th component of $y(t)$ is expressed as

$$
\mathrm{y}_{\mathrm{i}}(\mathrm{t})=\mathrm{d}_{\mathrm{i}} \mathrm{s}_{\mathrm{p}_{\mathrm{i}}}\left(\mathrm{t}-l_{\mathrm{i}}\right), \quad \mathrm{i}=1, \ldots, \mathrm{n},
$$

where $\left\{p_{1}, \ldots, p_{n}\right\}$ is an arbitrary permutation of $\{1, \ldots, n\}$. Therefore, we formulate the blind deconvolution problem as follows: Our objective is to find a matrix $\mathbf{W}_{0}(\mathrm{z})$ satisfying (7) without knowing the transfer function $\mathbf{H}(\mathrm{z})$ along with the source signals $\mathrm{s}_{\mathrm{i}}(\mathrm{t})^{\prime}$ 's. [If the transfer function $\mathrm{G}(\mathrm{z})$ becomes $\mathrm{G}_{0}(\mathrm{z}), \mathrm{G}(\mathrm{z})$ is said to be transparent.]

To find a matrix $\mathbb{W}_{0}(z)$, we make the following assumptions.

(A1) The transfer function $\mathbf{H}(\mathrm{z})$ in (2) is of full column rank for all nonzero complex $z \neq \infty$ (which implies that the unknown system of (2) has less inputs than outputs, that is, $\mathrm{m} \geq \mathrm{n}$ ).

(A2) The input sequence $\{\mathrm{s}(\mathrm{t})\}$ is a zero-mean, nonzerovariance stationary vector process whose component processes $\left\{\mathrm{s}_{\mathrm{i}}(\mathrm{t})\right\}(\mathrm{i}=1, \ldots, \mathrm{n})$ are temporally secondorder white and spatially second- and fourth-order uncorrelated. No more than one of the components of $\{\mathrm{s}(\mathrm{t})\}$ is Gaussian, and all the others are nonGaussian with

$$
\sum_{\tau_{1}, \tau_{2}, \tau_{3} \in Z}\left|\mathrm{Cs}_{\mathrm{i}}\left(\tau_{1}, \tau_{2}, \tau_{3}\right)\right|^{2} \neq 0(<\infty) \quad(\mathrm{i}=1, \ldots, \mathrm{n})
$$

where $\mathrm{Z}$ denotes the set of all integers, and $\operatorname{Cv}\left(\tau_{1}, \tau_{2}, \tau_{3}\right)$ is the fourth-order auto-cumulant of signal $v(t)$ defined by $\operatorname{Cv}\left(\tau_{1}, \tau_{2}, \tau_{3}\right):=\operatorname{cum}\left\{v(t), v\left(t+\tau_{1}\right)^{*}, v\left(t+\tau_{2}\right), v\left(t+\tau_{3}\right)^{*}\right\}$. Here the superscript $*$ denotes the complex conjugate.

(A3) The transfer function $\mathrm{W}(\mathrm{z})$ in (4) is an MIMO-FIR filter.

Remark 1: The assumption (9) in (A2) is weaker than the assumption for the source signals in [9], that is, $\operatorname{Cs}_{\mathrm{i}}(0,0,0) \neq$ 0 .

Under these assumptions, we attempt to solve the blind deconvolution problem.

\section{The non-deflation method}

We proved the following theorem [9].

Theorem 1: Let $\mathbf{H}(\mathrm{z})$ and $\{\mathbf{s}(\mathrm{t})\}$ satisfy (A1) and (A2), respectively. Suppose that $\mathrm{G}(\mathrm{z})$ is a paraunitary matrix. Then, maximizing the following criterion function (10) makes $\mathrm{G}(\mathrm{z})$ transparent.

$$
\mathrm{Q}_{1}:=\sum_{\mathrm{i}=1}^{\mathrm{n}} \mathrm{K} \mathrm{y}_{\mathrm{i}}
$$

where, $\mathrm{Ky}_{\mathrm{i}}:=\sum_{\tau_{1}, \tau_{2}, \tau_{3} \in \mathrm{Z}}\left|\mathrm{Cy} \mathrm{y}_{\mathrm{i}}\left(\tau_{1}, \tau_{2}, \tau_{3}\right)\right|^{2}$

In [9], we did not propose any algorithms 
implementing criterion (10). In this section, in order to propose the algorithms, we use the non-deflation approach whose objective is to extract simultaneously the inputs $\left\{\mathrm{s}_{\mathrm{i}}(\mathrm{t})\right\}(\mathrm{i}=1, \ldots, \mathrm{n})$ of the unknown multichannel system from the observed signals $\left\{\mathrm{x}_{\mathrm{i}}(\mathrm{t})\right\}(\mathrm{i}=1, \ldots, \mathrm{m})$. To apply the non-deflation approach using the criterion to the blind deconvolution problem, we consider the following function:

where

$$
\mathrm{Q}_{\mathrm{A}}=-\mathrm{Q}_{1}+\mathrm{Q}_{2}+\mathrm{Q}_{3} \text {, }
$$

$$
\begin{aligned}
& \mathrm{Q}_{2}=\frac{1}{2} \sum_{\tau=0}^{\infty}\left(\mathrm{E}\left[\mathrm{y}_{\mathrm{i}}(\mathrm{t}) \mathrm{y}_{\mathrm{i}}(\mathrm{t}-\tau)^{*}\right]-\delta(\tau)\right)^{2}, \\
& \mathrm{Q}_{3}=\frac{1}{2} \sum_{\substack{\mathrm{i}, \mathrm{j}=1 \\
\mathrm{i} \neq \mathrm{j}}}^{\mathrm{n}} \sum_{\tau=0}^{\infty} \mathrm{E}\left[\mathrm{y}_{\mathrm{i}}(\mathrm{t}) \mathrm{y}_{\mathrm{j}}(\mathrm{t}-\tau)^{*}\right]^{2} .
\end{aligned}
$$

Here $E[x]$ denotes the expectation of $x, Q_{2}$ is a penalty function which evaluates the auto- correlations of $y_{i}(t)(i=$ $1, \ldots, \mathrm{n}), \delta(\tau)$ denotes the Kronecker delta, and $\mathrm{Q}_{3}$ is a penalty function which evaluates the correlations between $y_{i}(t)$ and $y_{j}(t)(i, j=1, \ldots, n ; i \neq j)$.

Remark 2: The transfer function $G(z)$ becomes a paraunitary matrix, if and only if functions $Q_{2}$ and $Q_{3}$ take minimum values (zeros).

From Theorem 1 and Remark 2, if $\mathrm{Q}_{\mathrm{A}}$ takes a minimum, the blind deconvolution can be achieved. To minimize $Q_{A}$, taking into account the fact that the gradient of the criterion function $Q_{A}$ with respect to the matrix $W$ is given by

$$
\nabla_{\mathrm{W}} \mathrm{Q}_{\mathrm{A}}=-2 \frac{\partial \mathrm{Q}_{\mathrm{A}}}{\partial \mathrm{W}^{*}},
$$

see [11, p.890], we derive the following "online" stochastic gradient decent learning rule:

$$
\Delta \mathrm{w}_{\mathrm{ij}}^{(\mathrm{k})} \propto \alpha_{1} \frac{\partial \mathrm{Q}_{1}}{\partial \mathrm{w}_{\mathrm{ij}}^{(\mathrm{k})^{*}}}-\alpha_{2} \frac{\partial \mathrm{Q}_{2}}{\partial \mathrm{w}_{\mathrm{ij}}^{(\mathrm{k})^{*}}}-\alpha_{3} \frac{\partial \mathrm{Q}_{3}}{\partial \mathrm{w}_{\mathrm{ij}}^{(\mathrm{k})^{*}}} .
$$

where $w_{i i j)}^{(k)}$ are the parameters of the element $w_{i j}(z)$ $=\sum_{\mathrm{k}=0}^{\mathrm{L}} \mathrm{W}_{\mathrm{ij}}^{(\mathrm{ki})} \mathrm{z}^{\mathrm{k}}$ of $\mathrm{W}(\mathrm{z})$ and $\alpha_{\mathrm{i}}(\mathrm{i}=1,2,3)$ are positive constants that regulate the step size. On the calculation of the derivative of a scalar function with respect to complexvalued parameters, see [11] (p. 890). Calculating the right-hand side of (14), we have

$$
\begin{aligned}
& \Delta \mathrm{w}_{\mathrm{ij}}^{(\mathrm{k})} \propto \alpha_{1} \sum_{\tau_{1}, \tau_{2}, \tau_{3} \in \mathrm{Z}}\left[\mathrm{Cy} \mathrm{y}_{\mathrm{i}}\left(\tau_{1}, \tau_{2}, \tau_{3}\right)\right. \\
& \times\left\{\mathrm{E}\left[\mathrm{y}_{\mathrm{i}}(\mathrm{t}) \mathrm{y}_{\mathrm{i}}\left(\mathrm{t}+\tau_{2}\right) \mathrm{y}_{\mathrm{i}}\left(\mathrm{t}+\tau_{3}\right)^{*} \mathrm{x}_{\mathrm{j}}\left(\mathrm{t}+\mathrm{k}+\tau_{1}\right)^{*}\right]\right. \\
&+\mathrm{E}\left[\mathrm{y}_{\mathrm{i}}(\mathrm{t}) \mathrm{y}_{\mathrm{i}}\left(\mathrm{t}+\tau_{1}\right)^{*} \mathrm{y}_{\mathrm{i}}\left(\mathrm{t}+\tau_{2}\right) \mathrm{x}_{\mathrm{j}}\left(\mathrm{t}+\mathrm{k}+\tau_{3}\right)^{*}\right] \\
&-\mathrm{E}\left[\mathrm{y}_{\mathrm{i}}\left(\mathrm{t}+\tau_{2}\right) \mathrm{y}_{\mathrm{i}}\left(\mathrm{t}+\tau_{3}\right)^{*}\right] \mathrm{E}\left[\mathrm{y}_{\mathrm{i}}(\mathrm{t}) \mathrm{x}_{\mathrm{j}}\left(\mathrm{t}+\mathrm{k}+\tau_{1}\right)^{*}\right] \\
&-\mathrm{E}\left[\mathrm{y}_{\mathrm{i}}(\mathrm{t}) \mathrm{y}_{\mathrm{i}}\left(\mathrm{t}+\tau_{1}\right)^{*}\right] \mathrm{E}\left[\mathrm{y}_{\mathrm{i}}\left(\mathrm{t}+\tau_{2}\right) \mathrm{x}_{\mathrm{j}}\left(\mathrm{t}+\mathrm{k}+\tau_{1}\right)^{*}\right] \\
&-\mathrm{E}\left[\mathrm{y}_{\mathrm{i}}(\mathrm{t}) \mathrm{y}_{\mathrm{i}}\left(\mathrm{t}+\tau_{2}\right)\right]\left(\mathrm{E}\left[\mathrm{y}_{\mathrm{i}}\left(\mathrm{t}+\tau_{3}\right)^{*} \mathrm{x}_{\mathrm{j}}\left(\mathrm{t}+\mathrm{k}+\tau_{1}\right)^{*}\right]\right.
\end{aligned}
$$

$$
\begin{array}{r}
\left.+E\left[y_{i}\left(t+\tau_{1}\right)^{*} x_{j}\left(t+k+\tau_{3}\right)^{*}\right]\right) \\
-E\left[y_{i}\left(t+\tau_{1}\right)^{*} y_{i}\left(t+\tau_{2}\right)\right] E\left[y_{i}(t) x_{j}\left(t+k+\tau_{3}\right)^{*}\right] \\
\left.\left.-E\left[y_{i}(t) y_{i}\left(t+\tau_{3}\right)^{*}\right] E\left[y_{i}\left(t+\tau_{2}\right) x_{j}\left(t+k+\tau_{1}\right)^{*}\right]\right\}\right] \\
-\alpha_{2}\left\{\left(E\left[y_{i}(t) y_{i}(t)^{*}\right]-1\right) E\left[y_{i}(t) x_{j}(t+k)^{*}\right]\right. \\
\left.+\sum_{\substack{\tau=1 \\
-\alpha}}^{\infty} E\left[y_{i}(t) y_{i}(t+\tau)^{*}\right] E\left[y_{i}(t) x_{j}(t+k+\tau)^{*}\right]\right\} \\
\left.\sum_{\substack{k=1 \\
k \neq i}}^{n} E\left[y_{k}(t) y_{i}(t+\tau)^{*}\right] E\left[y_{k}(t) x_{j}(t+k+\tau)^{*}\right]\right\},(
\end{array}
$$

Here, let us summarize the non-deflation algorithm.

Step 1. Compute the outputs $y_{i}(t)(i=1, \ldots, n)$ of the equalizer using (3).

Step 2. Compute $\mathrm{Cy}_{\mathrm{i}}\left(\tau_{1}, \tau_{2}, \tau_{3}\right), \quad \mathrm{E}\left[\mathrm{y}_{\mathrm{i}}\left(\mathrm{t}+\tau_{2}\right) \mathrm{y}_{\mathrm{i}}\left(\mathrm{t}+\tau_{3}\right)^{*}\right]$, $\mathrm{E}\left[\mathrm{y}_{\mathrm{i}}(\mathrm{t}) \mathrm{y}_{\mathrm{i}}\left(\mathrm{t}+\tau_{1}\right) *\right], \quad \mathrm{E}\left[\mathrm{y}_{\mathrm{i}}(\mathrm{t}) \mathrm{y}_{\mathrm{i}}\left(\mathrm{t}+\tau_{2}\right)\right], \quad \mathrm{E}\left[\mathrm{y}_{\mathrm{i}}\left(\mathrm{t}+\tau_{1}\right) * \mathrm{y}_{\mathrm{i}}\left(\mathrm{t}+\tau_{2}\right)\right]$, $\mathrm{E}\left[\mathrm{y}_{\mathrm{i}}(\mathrm{t}) \mathrm{y}_{\mathrm{i}}\left(\mathrm{t}+\tau_{3}\right)^{*}\right], \mathrm{E}\left[\mathrm{y}_{\mathrm{i}}(\mathrm{t}) \mathrm{y}_{\mathrm{i}}(\mathrm{t})^{*}\right]$, and $\mathrm{E}\left[\mathrm{y}_{\mathrm{k}}(\mathrm{t}) \mathrm{y}_{\mathrm{i}}(\mathrm{t}+\tau)^{*}\right]$ in $(15)$ by using the moving average, e.g., $E\left[\mathrm{y}_{\mathrm{i}}\left(\mathrm{t}+\tau_{1}\right) * \mathrm{y}_{\mathrm{i}}\left(\mathrm{t}+\tau_{2}\right)\right]$ is estimated by

$$
\begin{aligned}
\phi_{\mathrm{ii}}\left(\tau_{1}, \tau_{2}, \mathrm{t}+1\right)= & \beta \phi_{\mathrm{ii}}\left(\tau_{1}, \tau_{2}, \mathrm{t}\right) \\
& +(1-\beta) \mathrm{y}_{\mathrm{i}}\left(\mathrm{t}+\tau_{1}\right)^{*} \mathrm{y}_{\mathrm{i}}\left(\mathrm{t}+\tau_{2}\right) \quad(0<\beta<1),
\end{aligned}
$$

with an appropriate initial value $\phi_{\mathrm{ii}}\left(\tau_{1}, \tau_{2}, 0\right)$.

Step 3. Modify $\mathrm{w}_{\mathrm{ij}}^{(\mathrm{k})}$ using the following equation:

$$
\begin{aligned}
& \Delta \mathrm{w}_{\mathrm{ij}}^{(\mathrm{k})} \propto \alpha_{1} \sum_{\tau_{1}, \tau_{2}, \tau_{3} \in \mathrm{Z}}\left[\phi_{C y_{\mathrm{i}}}\left(\tau_{1}, \tau_{2}, \tau_{3}\right)\right. \\
& \times\left\{\mathrm{y}_{\mathrm{i}}(\mathrm{t}) \mathrm{y}_{\mathrm{i}}\left(\mathrm{t}+\tau_{2}\right) \mathrm{y}_{\mathrm{i}}\left(\mathrm{t}+\tau_{3}\right) * \mathrm{x}_{\mathrm{j}}\left(\mathrm{t}+\mathrm{k}+\tau_{1}\right) *\right. \\
& +\mathrm{y}_{\mathrm{i}}(\mathrm{t}) \mathrm{y}_{\mathrm{i}}\left(\mathrm{t}+\tau_{1}\right)^{*} \mathrm{y}_{\mathrm{i}}\left(\mathrm{t}+\tau_{2}\right) \mathrm{x}_{\mathrm{j}}\left(\mathrm{t}+\mathrm{k}+\tau_{3}\right)^{*} \\
& -\phi_{\mathrm{ij}}\left(\tau_{2}, \tau_{3}, \mathrm{t}\right) \mathrm{y}_{\mathrm{i}}(\mathrm{t}) \mathrm{x}_{\mathrm{j}}\left(\mathrm{t}+\mathrm{k}+\tau_{1}\right)^{*}-\phi_{\mathrm{ii}}\left(0, \tau_{1}, \mathrm{t}\right) \mathrm{y}_{\mathrm{i}}\left(\mathrm{t}+\tau_{2}\right) \mathrm{x}_{\mathrm{j}}\left(\mathrm{t}+\mathrm{k}+\tau_{1}\right)^{*} \\
& -\phi_{\mathrm{ii}}\left(0, \tau_{2}, \mathrm{t}\right)\left(\mathrm{y}_{\mathrm{i}}\left(\mathrm{t}+\tau_{3}\right)^{*} \mathrm{x}_{\mathrm{j}}\left(\mathrm{t}+\mathrm{k}+\tau_{1}\right)^{*}+\mathrm{y}_{\mathrm{i}}\left(\mathrm{t}+\tau_{1}\right)^{*} \mathrm{x}_{\mathrm{j}}\left(\mathrm{t}+\mathrm{k}+\tau_{3}\right)^{*}\right) \\
& \left.\left.-\phi_{\mathrm{ij}}\left(\tau_{1}, \tau_{2}, \mathrm{t}\right) \mathrm{y}_{\mathrm{i}}(\mathrm{t}) \mathrm{x}_{\mathrm{j}}\left(\mathrm{t}+\mathrm{k}+\tau_{3}\right)^{*}-\phi_{\mathrm{ij}}\left(0, \tau_{3}, \mathrm{t}\right) \mathrm{y}_{\mathrm{i}}\left(\mathrm{t}+\tau_{2}\right) \mathrm{x}_{\mathrm{j}}\left(\mathrm{t}+\mathrm{k}+\tau_{1}\right)^{*}\right\}\right] \\
& -\alpha_{2}\left\{\left(\phi_{\text {ii }}(0,0, \mathrm{t})-1\right) \mathrm{y}_{\mathrm{i}}(\mathrm{t}) \mathrm{x}_{\mathrm{j}}(\mathrm{t}+\mathrm{k})^{*}\right. \\
& \left.+\sum_{\tau=1}^{\infty} \phi_{\mathrm{ii}}(0, \tau, \mathrm{t}) \mathrm{y}_{\mathrm{i}}(\mathrm{t}) \mathrm{x}_{\mathrm{j}}(\mathrm{t}+\mathrm{k}+\tau)^{*}\right\} \\
& -\alpha_{3}\left\{\sum_{\mathrm{k}=1}^{\mathrm{n}} \sum_{\tau=0}^{\infty} \phi_{\mathrm{ki}}(0, \tau, \mathrm{t}) \mathrm{y}_{\mathrm{k}}(\mathrm{t}) \mathrm{x}_{\mathrm{j}}(\mathrm{t}+\mathrm{k}+\tau)^{*}\right\} \text {, }
\end{aligned}
$$

where $(16)$ is obtained by applying (15) to a stochastic gradient approach. Here $\phi_{\mathrm{Cy}_{\mathrm{i}}}\left(\tau_{1}, \tau_{2}, \tau_{3}\right)$ computed by using the moving average is the estimation of $\mathrm{Cy}_{\mathrm{i}}\left(\tau_{1}, \tau_{2}, \tau_{3}\right)$.

Step 4. Repeat the first three steps until the learning sufficiently converges.

\section{The deflation method}

In this section, we propose a deflation algorithm using the criterion function (10) for the blind separation of MIMO 
constant channels. [Unfortunately we have not yet worked out any criterion for achieving the blind deconvolution of MIMO-FIR channels by using deflation approaches.] We consider, therefore, the following MIMO constant system:

$$
x(t)=H^{(0)} s(t),
$$

where (17) is given by putting $\mathrm{K}=0$ in (1). The problem is to separate $s(t)$ from $\mathbf{x}(t)$ without knowing $H^{(0)}$ and observing $s(t)$.

The deflation approach can recover $\left\{\mathrm{s}_{i}(\mathrm{t})\right\}(\mathrm{i}=1, \ldots, \mathrm{n})$ one by one from $\left\{\mathrm{x}_{\mathrm{i}}(\mathrm{t})\right\}(\mathrm{i}=1, \ldots, \mathrm{m})$. In this approach, we first apply a maximization criterions to the outputs of the unknown multichannel system with $m$ outputs and $n$ inputs to extract only one source signal, and estimate the contribution of the extracted source signal to the output signals. Then, we remove this contribution from the output signals to define the outputs of a multichannel system with $m$ outputs and $n-1$ inputs. We again apply the maximization criterion to the outputs of the unknown multichannel system with $m$ outputs and $n-1$ inputs to extract the next source signal. We continue this process until we extract the last source signal.

To implement the idea of the deflation approach, a low vector $\mathbf{w}=\left[\mathrm{w}_{1}, \ldots, \mathrm{w}_{\mathrm{m}}\right]$ of the matrix $\mathbf{W}^{(0)}$ is used for representing the parameters of an equalizer. Therefore, the output of the equalizer is given by

$$
\begin{aligned}
y(t) & =w x(t) \\
& =g s(t),
\end{aligned}
$$

where $g(z)=\left[g_{1}, \ldots, g_{n}\right]$ is a low vector of the matrix $G^{(0)}$. Criterion (10) is modified to the following criterion function.

$$
\mathrm{Q}_{4}=\frac{1}{2} \mathrm{Ky}
$$

Here, we present the following theorem.

Theorem 2: Under $\mathrm{gg}^{*^{\mathrm{T}}}=1$, the deflation algorithm of maximizing criterion $\mathrm{Q}_{4}$ gives a solution to the blind separation problem, that is,

$$
\begin{aligned}
\mathrm{g}_{\mathrm{i}} & =\mathrm{c} & & \text { for some } \mathrm{i}=\mathrm{i}_{0} \\
& =0 & & \text { for } \mathrm{i} \neq \mathrm{i}_{0}
\end{aligned}
$$

where $\mathrm{c}$ is a constant with unit magnitude $|\mathrm{c}|=1$ and $\mathrm{i}_{0}=\arg$ $\max _{\{\mathrm{i}=1,2, \ldots, \mathrm{n}\}} \mathrm{Ks}_{\mathrm{i}}$.

The outline of the proof of Theorem 2 is given by Appendix. Note that $\mathrm{gg}^{* \mathrm{~T}}=1$ implies that the variance of output signal $\mathrm{y}(\mathrm{t})$ is unit and $\arg \max _{\{\mathrm{i}=1,2, \ldots, \mathrm{n}\}} \mathrm{Ks}_{\mathrm{i}}$ is the value of number $\mathrm{i} \in\{1,2, \ldots, \mathrm{n}\}$ that maximizes $\mathrm{Ks}_{\mathrm{j}}$.

Based on Theorem 2, by applying the deflation approach to the blind separation problem, we propose the following minimization criterion:

where

$$
\mathrm{Q}_{\mathrm{B}}=-\mathrm{Q}_{4}+\mathrm{Q}_{5} \text {, }
$$

$$
\mathrm{Q}_{5}=\frac{1}{2}\left(\mathrm{E}\left[\mathrm{y}(\mathrm{t}) \mathrm{y}(\mathrm{t})^{*}\right]-1\right)^{2}
$$

Here $Q_{5}$ is a penalty term added to satisfy the constraint $\operatorname{gg}^{* \mathrm{~T}}=1$.
Remark 3: The constraint gg $^{* \mathrm{~T}}=1$ holds, if and only if function $\mathrm{Q}_{5}$ takes a minimum (zero).

From Theorem 2 and Remark 3, one can see that if $\mathrm{Q}_{\mathrm{B}}$ takes a minimum, the blind deconvolution can be achieved. In order to minimize $\mathrm{Q}_{\mathrm{B}}$, we use the same rule as (14);

$$
\Delta \mathrm{w}_{\mathrm{i}} \propto \alpha_{4} \frac{\partial \mathrm{Q}_{4}}{\partial \mathrm{w}_{\mathrm{i}}^{*}}-\alpha_{5} \frac{\partial \mathrm{Q}_{5}}{\partial \mathrm{w}_{\mathrm{i}}^{*}} .
$$

where $\alpha_{i}(i=4,5)$ are positive constants that regulate the step size. Calculating the right-hand side of (22), we have

$$
\begin{aligned}
& \Delta \mathrm{w}_{\mathrm{i}} \propto \alpha_{4} \sum_{\tau_{1}, \tau_{2}, \tau_{3} \in \mathrm{Z}}\left[\mathrm{Cy}\left(\tau_{1}, \tau_{2}, \tau_{3}\right)\right. \\
& \times\left\{\mathrm{E}\left[\mathrm{y}(\mathrm{t}) \mathrm{y}\left(\mathrm{t}+\tau_{2}\right) \mathrm{y}\left(\mathrm{t}+\tau_{3}\right)^{*} \mathrm{x}_{\mathrm{i}}\left(\mathrm{t}+\tau_{1}\right)^{*}\right]\right. \\
& +E\left[y(t) y\left(t+\tau_{1}\right)^{*} y\left(t+\tau_{2}\right) x_{i}\left(t+\tau_{3}\right)^{*}\right] \\
& -E\left[y\left(t+\tau_{2}\right) y\left(t+\tau_{3}\right)^{*}\right] E\left[y(t) x_{i}\left(t+\tau_{1}\right)^{*}\right] \\
& -E\left[y(t) y\left(t+\tau_{1}\right)^{*}\right] E\left[y\left(t+\tau_{2}\right) x_{i}\left(t+\tau_{1}\right)^{*}\right] \\
& -E\left[y(t) y\left(t+\tau_{2}\right)\right]\left(E\left[y\left(t+\tau_{3}\right) * x_{i}\left(t+\tau_{1}\right) *\right]\right. \\
& \left.+\mathrm{E}\left[\mathrm{y}\left(\mathrm{t}+\tau_{1}\right) * \mathrm{x}_{\mathrm{i}}\left(\mathrm{t}+\tau_{3}\right) *\right]\right) \\
& -E\left[y\left(t+\tau_{1}\right)^{*} y\left(t+\tau_{2}\right)\right] E\left[y(t) x_{i}\left(t+\tau_{3}\right)^{*}\right] \\
& \left.\left.-\mathrm{E}\left[\mathrm{y}(\mathrm{t}) \mathrm{y}\left(\mathrm{t}+\tau_{3}\right)^{*}\right] \mathrm{E}\left[\mathrm{y}\left(\mathrm{t}+\tau_{2}\right) \mathrm{x}_{\mathrm{i}}\left(\mathrm{t}+\tau_{1}\right)^{*}\right]\right\}\right] \\
& -\alpha_{5}\left\{\left(\mathrm{E}\left[\mathrm{y}(\mathrm{t}) \mathrm{y}(\mathrm{t})^{*}\right]-1\right) \mathrm{E}\left[\mathrm{y}(\mathrm{t}) \mathrm{x}_{\mathrm{i}}(\mathrm{t})^{*}\right]\right.
\end{aligned}
$$

Here, let us summarize an iterative procedure of extracting the source signals from the observed signals by using the deflation approach.

Step 1. Compute the output $y(t)$ of the equalizer, using (18).

Step 2. Compute $\mathrm{Cy}\left(\tau_{1}, \tau_{2}, \tau_{3}\right), \quad \mathrm{E}\left[\mathrm{y}\left(\mathrm{t}+\tau_{2}\right) \mathrm{y}\left(\mathrm{t}+\tau_{3}\right)^{*}\right]$, $\mathrm{E}\left[\mathrm{y}(\mathrm{t}) \mathrm{y}\left(\mathrm{t}+\tau_{1}\right)^{*}\right], \quad \mathrm{E}\left[\mathrm{y}(\mathrm{t}) \mathrm{y}\left(\mathrm{t}+\tau_{2}\right)\right], \quad \mathrm{E}\left[\mathrm{y}\left(\mathrm{t}+\tau_{1}\right)^{*} \mathrm{y}\left(\mathrm{t}+\tau_{2}\right)\right]$, $\mathrm{E}\left[\mathrm{y}(\mathrm{t}) \mathrm{y}\left(\mathrm{t}+\tau_{3}\right)^{*}\right]$, and $\mathrm{E}\left[\mathrm{y}(\mathrm{t}) \mathrm{y}(\mathrm{t})^{*}\right]$ in (23) by using the moving average. For example, $\mathrm{E}\left[\mathrm{y}\left(\mathrm{t}+\tau_{2}\right) \mathrm{y}\left(\mathrm{t}+\tau_{3}\right)^{*}\right]$ is estimated by using the following rule:

$$
\begin{aligned}
\phi\left(\tau_{2}, \tau_{3}, \mathrm{t}+1\right) & =\beta \phi\left(\tau_{2}, \tau_{3}, \mathrm{t}\right) \\
+ & (1-\beta) \mathrm{y}\left(\mathrm{t}+\tau_{2}\right) \mathrm{y}\left(\mathrm{t}+\tau_{3}\right)^{*} \quad(0<\beta<1),
\end{aligned}
$$

with an appropriate initial value $\phi\left(\tau_{2}, \tau_{3}, 0\right)$.

Step 3. Modify $\mathrm{w}_{\mathrm{i}}$ using the following equation:

$$
\begin{aligned}
& \Delta \mathrm{w}_{\mathrm{i}} \propto \alpha_{4} \sum_{\tau_{1}, \tau_{2}, \tau_{3} \in \mathrm{Z}}\left[\left|\phi_{\mathrm{Cy}}\left(\tau_{1}, \tau_{2}, \tau_{3}\right)\right|\right. \\
& \times\left\{\mathrm{y}(\mathrm{t}) \mathrm{y}\left(\mathrm{t}+\tau_{2}\right) \mathrm{y}\left(\mathrm{t}+\tau_{3}\right)^{*} \mathrm{x}_{\mathrm{i}}\left(\mathrm{t}+\tau_{1}\right)^{*}+\right. \\
& y(\mathrm{t}) \mathrm{y}\left(\mathrm{t}+\tau_{1}\right)^{*} \mathrm{y}\left(\mathrm{t}+\tau_{2}\right) \mathrm{x}_{\mathrm{i}}\left(\mathrm{t}+\tau_{3}\right)^{*} \\
& -\phi\left(\tau_{2}, \tau_{3}, \mathrm{t}\right) \mathrm{y}(\mathrm{t}) \mathrm{x}_{\mathrm{j}}\left(\mathrm{t}+\tau_{1}\right)^{*}-\phi\left(0, \tau_{1}, \mathrm{t}\right) \mathrm{y}\left(\mathrm{t}+\tau_{2}\right) \mathrm{x}_{\mathrm{i}}\left(\mathrm{t}+\tau_{1}\right)^{*} \\
& -\phi\left(0, \tau_{2}, \mathrm{t}\right)\left(\mathrm{y}\left(\mathrm{t}+\tau_{3}\right)^{*} \mathrm{x}_{\mathrm{i}}\left(\mathrm{t}+\tau_{1}\right)^{*}+\mathrm{y}\left(\mathrm{t}+\tau_{1}\right)^{*} \mathrm{x}_{\mathrm{i}}\left(\mathrm{t}+\tau_{3}\right)^{*}\right)
\end{aligned}
$$




$$
\begin{aligned}
& \left.\left.-\phi\left(\tau_{1}, \tau_{2}, \mathrm{t}\right) \mathrm{y}(\mathrm{t}) \mathrm{x}_{\mathrm{i}}\left(\mathrm{t}+\tau_{3}\right)^{*}-\phi\left(0, \tau_{3}, \mathrm{t}\right) \mathrm{y}\left(\mathrm{t}+\tau_{2}\right) \mathrm{x}_{\mathrm{i}}\left(\mathrm{t}+\tau_{1}\right)^{*}\right\}\right] \\
& -\alpha_{5}\left\{(\phi(0,0, \mathrm{t})-1) \mathrm{y}(\mathrm{t}) \mathrm{x}_{\mathrm{i}}(\mathrm{t})^{*}\right.
\end{aligned}
$$

where (24) is obtained by applying (23) to a stochastic gradient approach. Here $\phi_{\mathrm{Cy}}\left(\tau_{1}, \tau_{2}, \tau_{3}\right)$ computed by using the moving average is the estimation of $\mathrm{Cy}\left(\tau_{1}, \tau_{2}, \tau_{3}\right)$.

Step 4. Repeat the first above three steps until the learning sufficiently converges. If the learning converges, go to the next step.

Step 5. Assume that the source signal $s_{p_{i}}(t)$ is recovered. Compute the scale of the input $s_{p_{i}}(t)$ by using the following equation:

$$
v(t)=\sum_{j=1}^{m} w_{j 0} x_{j}(t),
$$

where $\mathrm{w}_{\mathrm{j} 0}$ 's are the parameters of the vector $\mathrm{w}_{0}$ obtained by the first three steps.

Step 6. Estimate the scale of $h_{q p}^{(0)}$ by using the crosscorrelation of the observed signals $x_{q}(t)$ 's and $v(t)$ 's as

$$
\hat{\mathrm{h}}_{\mathrm{qp}_{\mathrm{i}}}^{(0)}:=\mathrm{E}\left[\mathrm{x}_{\mathrm{q}}(\mathrm{t}) \mathrm{v}(\mathrm{t})^{*}\right], \quad(\mathrm{q}=1,2, \ldots, \mathrm{m}) .
$$

where $h_{i j}^{(0)}$ is an element of the matrix $\mathbb{H}^{(0)}$.

Step 7. Estimate the contribution of $s_{p_{i}}(t)$ to the observed signals $x_{q}(t)(q=1,2, \ldots, m)$, that is, $h_{q p_{i}} s_{p_{i}}(t)$, using

$$
\hat{\mathrm{x}}_{\mathrm{qp}_{\mathrm{i}}}(\mathrm{t})=\hat{\mathrm{h}}_{\mathrm{qp}_{\mathrm{i}}}^{(0)} v(\mathrm{t}), \quad(\mathrm{q}=1,2, \ldots, \mathrm{m}) .
$$

Step 8. Remove the above contribution using the following equation:

$$
x_{q}^{(i)}(t)=x_{q}(t)-\hat{x}_{q_{p} i}(t), \quad(q=1,2, \ldots, m) .
$$

where $\mathrm{x}_{\mathrm{q}}^{(\mathrm{i})}(\mathrm{t})(\mathrm{q}=1, \ldots, \mathrm{m})$ are the outputs of a linear unknown multichannel system with $m$ outputs and $n-1$ inputs.

Step 9. If the superscript (i) of $x_{q}{ }^{(i)}(t)$ is less than $n$, then set $\mathrm{i}=\mathrm{i}+1$ and $\mathrm{x}_{\mathrm{q}}(\mathrm{t})=\mathrm{x}_{\mathrm{q}}{ }^{(\mathrm{i})}(\mathrm{t})(\mathrm{q}=1, \ldots, \mathrm{m})$, and go to Step 1 . If $\mathrm{i}=\mathrm{n}$, then stop here.

For the details of the above Step 5 to Step 9, see [10].

\section{Computer Simulations}

We carried out some computer simulations to demonstrate the validity of our proposed algorithms. This section describes two of them.

\section{Example 1 (Non-deflation algorithm)}

In this example, we show the computer simulation result of the blind deconvolution obtained by using the nondeflation algorithm. We considered the following twoinput and three-output FIR system.

$$
H(z)=\left[\begin{array}{l}
h_{11}(z) h_{12}(z) \\
h_{21}(z) h_{22}(z) \\
h_{31}(z) h_{32}(z)
\end{array}\right]=\left[\begin{array}{cc}
0.5 & z \\
z & 1 \\
1 & 0.5 z
\end{array}\right] .
$$

The observed signal $x(t)=\left[x_{1}(t), x_{2}(t), x_{3}(t)\right]^{T}$ was calculated by (2). The source signals $\left\{\mathrm{s}_{\mathrm{i}}(\mathrm{t})\right\}(\mathrm{i}=1,2)$ were generated by the following system:

$$
\left[\begin{array}{l}
s_{1}(t) \\
s_{2}(t)
\end{array}\right]=\left[\begin{array}{cc}
\frac{0.7+z}{1+0.7 z} & 0 \\
0 & \frac{0.3+z}{1+0.3 z}
\end{array}\right]\left[\begin{array}{l}
v_{1}(t) \\
v_{2}(t)
\end{array}\right]
$$

where $\left\{v_{1}(t)\right\}$ and $\left\{v_{2}(t)\right\}$ were non-Gaussian i.i.d. signals with zero mean and unit variance, but were independent with each other. Since the filters $(0.7+z) /(1+0.7 z)$ and $(0.3+z) /(1+0.3 z)$ in $(29)$ were all-pass filters, the source signals $\left\{\mathrm{s}_{1}(\mathrm{t})\right\}$ and $\left\{\mathrm{s}_{2}(\mathrm{t})\right\}$ became temporally second-order white but temporally fourth-order colored signals.

The order of the equalizer in (3) was set to $L=1$. We used the three-input and two-output FIR system as the equalizer. The values of $\tau_{1}, \tau_{2}$, and $\tau_{3}$ in $Q_{1}$ were set to $[0,2],[0,2]$, and $[0,2]$, respectively. The values of the parameters $\tau$ in $Q_{2}$ and $Q_{3}$ were set to $[0,2]$ and $[0,2]$, respectively. The parameters $\alpha_{1}, \alpha_{2}$, and $\alpha_{3}$ of the learning algorithm were set to $0.0000001,0.001,0.0005$, respectively (see (16)). The initial values of $w_{i j}^{\mathrm{k}}(i=1,2$; $\mathrm{j}=1,2,3 ; \mathrm{k}=0,1)$ were set to zero except for $\mathrm{w}_{11}=1$ and $\mathrm{w}_{23}^{0}=1$.

The following equalizer $W_{0}(z)$ was found after 100000 iterations using the procedure of Step 1 to Step 4 in the nondeflation approach:

$$
\begin{array}{r}
W_{0}(z)=\left[\begin{array}{ccc}
1.2683 & -0.0117 & -0.5840 \\
-0.6569 & -0.0223 & 1.2945
\end{array}\right] \\
+\left[\begin{array}{ccc}
0.0099 & 0.0018 & 0.0017 \\
-0.0329 & -0.0219 & 0.0096
\end{array}\right] \mathrm{z}
\end{array}
$$

Therefore, the output signals $\mathrm{y}_{1}(\mathrm{t})$ and $\mathrm{y}_{2}(\mathrm{t})$, respectively, were

$$
\begin{aligned}
\mathrm{y}_{1}(\mathrm{t})= & 0.0502 \mathrm{~s}_{1}(\mathrm{t})-0.0051 \mathrm{~s}_{1}(\mathrm{t}-1)+0.0018 \mathrm{~s}_{1}(\mathrm{t}-2) \\
& -0.0117 \mathrm{~s}_{2}(\mathrm{t})+0.9781 \mathrm{~s}_{2}(\mathrm{t}-1)+0.0107 \mathrm{~s}_{2}(\mathrm{t}-2) \\
\approx & \mathrm{s}_{2}(\mathrm{t}-1), \\
\mathrm{y}_{2}(\mathrm{t})= & 0.9661 \mathrm{~s}_{1}(\mathrm{t})-0.0291 \mathrm{~s}_{1}(\mathrm{t}-1)-0.0219 \mathrm{~s}_{1}(\mathrm{t}-2) \\
& -0.0223 \mathrm{~s}_{2}(\mathrm{t})-0.0315 \mathrm{~s}_{2}(\mathrm{t}-1)-0.0281 \mathrm{~s}_{2}(\mathrm{t}-2) \\
\approx & \mathrm{s}_{1}(\mathrm{t}) .
\end{aligned}
$$

From this result, it can be seen that our proposed nondeflation algorithm can achieve the blind deconvolution.

\section{Example 2 (Deflation algorith $\mathrm{m}$ )}

In the example 2, we show the computer simulation result of the deflation algorithm. The channel matrix $\mathbf{H}^{(0)}$ was set to 


$$
\mathbf{H}^{(0)}=\left[\begin{array}{l}
\mathrm{h}_{11}^{(0)} \mathrm{h}_{12}^{(0)} \\
\mathrm{h}_{21}^{(0)} \mathrm{h}_{22}^{(0)} \\
\mathrm{h}_{31}^{(0)} \mathrm{h}_{32}^{(0)}
\end{array}\right]=\left[\begin{array}{cc}
-0.6 & 0.1 \\
-0.3 & 0.2 \\
0.8 & -1.7
\end{array}\right] .
$$

The observed signal $x(t)=\left[\begin{array}{lll}x_{1}(t), & x_{2}(t), & x_{3}(t)\end{array}\right]^{T}$ was calculated by (17). The source signals $\left\{\mathrm{s}_{\mathrm{i}}(\mathrm{t})\right\} \quad(\mathrm{i}=1,2)$ were generated by the following system:

$$
\left[\begin{array}{l}
\mathrm{s}_{1}(\mathrm{t}) \\
\mathrm{s}_{2}(\mathrm{t})
\end{array}\right]=\left[\begin{array}{cc}
1 & 0 \\
0 & \frac{0.3+\mathrm{z}}{1+0.3 \mathrm{z}}
\end{array}\right]\left[\begin{array}{l}
\psi_{1}(\mathrm{t}) \\
\psi_{2}(\mathrm{t})
\end{array}\right] .
$$

where the first component signal $\left\{\psi_{1}(t)\right\}$ was a Gaussian white signal and the second component signal $\left\{\psi_{2}(t)\right\}$ was a non-Gaussian, i.i.d. signal with zero mean and unit variance. The source signal $\left\{\mathrm{s}_{2}(\mathrm{t})\right\}$ was temporally second-order white but temporally fourth-order colored signal.

The values of $\tau_{1}, \tau_{2}$, and $\tau_{3}$ in $\mathrm{Q}_{4}$ were set to $[0,2],[0,2]$, and $[0,2]$, respectively. The value of the parameter $\tau$ in $\mathrm{Q}_{5}$ was set to $[0,2]$. The parameters of the learning algorithm were chosen as $\alpha_{4}=0.000001$ and $\alpha_{5}=0.001$ (see (24)). The output of the equalizer is calculated by $y(t)=$ $w_{1} x_{1}(t)+w_{2} x_{2}(t)+w_{3} x_{3}(t)$. The initial values of $w_{i}(i=1,2$, 3) were set to 0 except for $w_{1}=1$.

The following equalizer $\mathrm{w}_{0}$ was found after 500000 iterations using the procedure of Step1 to Step 4;

$$
\mathbf{w}_{0}=[-0.8359,0.1479,-0.5881]
$$

Therefore, the output of the equalizer was

$$
\begin{aligned}
\mathrm{y}(\mathrm{t}) & =-0.0133 \mathrm{~s}_{1}(\mathrm{t})+1.0049 \mathrm{~s}_{2}(\mathrm{t}) \\
& \approx \mathrm{s}_{2}(\mathrm{t})
\end{aligned}
$$

Since $\mathrm{Ks}_{2}>\mathrm{Ks}_{1}=0$, one can see that the deflation algorithm can be used to extract the source signal which has the largest energy of the fourth-order auto-cumulant sequences among the source signals. Moreover, we confirmed that the source signal $\left\{\mathrm{s}_{1}(\mathrm{t})\right\}$ was extracted by the procedure of Step 5 to Step 9.

\section{Conclusions}

We have proposed an iterative algorithm based on the non-deflation approach of the blind deconvolution for temporally second-order white and spatially second- and fourth-order uncorrelated signals. Moreover, we have presented an iterative algorithm based on the deflation approach for the blind separation of MIMO constant channels.

We have carried out computer simulations to demonstrate our proposed algorithms. The results have shown that the proposed algorithms could work well.

\section{References}

[1] Y. Inouye and T. Sato, Unconstrained optimization criteria for blind equalization of multichannel linear systems, in Proc. IEEE Workshop on Statistical Signal and Array Processing, Corfu, Greece, June 24-26, 1996.
[2] G. B. Giannakis, Y. Inouye, and J. M. Mendel, "Cumulantbased identification of multichannel moving-average processes," IEEE Trans. Automat. Contr., vol. 34, pp. 783-787, July 1989.

[3] Y. Inouye and T. Habe, "Blind deconvolution of multichannel linear time-invariant systems," Technical Reports of the Institute of Electronics, Information and Communication Engineers, vol. DSP 95-24, pp. 9-16, May 1995.

[4] P. Comon, "Contrasts for multichannel blind deconvolution," Signal Processing Letters, vol. 3, no. 7, pp. 209-211, July 1996.

[5] J. G. Proakis, Digital Communications, New York, NY: McGraw-Hill, 1995.

[6] P. P. Vaidyanathan, Multiple Systems and Filter Banks, Englewood Cliffs, New Jersey: Prentice-Hall, 1993.

[7] O. Shalvi and E. Weinstein, New criteria for blind deconvolution of nonmimimum phase systems (channels), IEEE Trans. Inform. Theory, vol. IT-32, no. 2, pp. 312-320, March 1990.

[8] Y. Inouye and R.-W. Liu, Criterion for direct blind deconvolution of MIMO FIR systems driven by white source signals, in Proc. ICASSP, Phoenix, AZ, 1999, vol. 5, pp. 2889-2892.

[9] R.-W. Liu and Y. Inouye, Direct blind deconvolution of multiuser-multichannel systems driven by temporally white source signals," submitted to IEEE Trans. Inform. Theory.

[10] Y. Inouye and K. Tanebe, Super-exponential algorithms for multichannel blind deconvolution, IEEE Trans. Signal Processing, vol. 48, no. 3, pp. 881-888, March 2000.

[11] S. Haykin, Adaptive Filter Theory, Prentice-Hall, Inc., 1996.

\section{Appendix: Outline of the proof of Theorem 2}

We can derive the following inequalities:

$$
\begin{aligned}
\mathrm{Ky} & \leq \sum_{\tau_{1}, \tau_{2}, \tau_{3} \in Z}\left\{\sum_{\mathrm{i}=1}^{\mathrm{n}}\left|\mathrm{g}_{\mathrm{i}}\right|^{4} \mathrm{Cs}_{\mathrm{i}}\left(\tau_{1}, \tau_{2}, \tau_{3}\right)\right\}^{2} \\
& \leq \mathrm{K}_{0}\left(\sum_{\mathrm{i}=1}^{\mathrm{n}}\left|\mathrm{g}_{\mathrm{i}}\right|^{4}\right)^{2} \leq \mathrm{K}_{0}\left\{\left(\sum_{\mathrm{i}=1}^{\mathrm{n}}\left|\mathrm{g}_{\mathrm{i}}\right|^{2}\right)^{2}\right\}^{2}
\end{aligned}
$$

where $\mathrm{K}_{0}=\max _{\{\mathrm{k}=1, \ldots, \mathrm{n}\}} \sum_{\tau_{1}, \tau_{2}, \tau_{3} \in \mathrm{Z}}\left|\mathrm{Cs}_{\mathrm{k}}\left(\tau_{1}, \tau_{2}, \tau_{3}\right)\right|^{2} . \quad$ Taking into account $\sum_{\mathrm{i}=1}^{\mathrm{n}}\left|\mathrm{g}_{\mathrm{i}}\right|^{2}=1$, we have

$$
\mathrm{K}_{0}\left\{\left(\sum_{\mathrm{i}=1}^{\mathrm{n}}\left|\mathrm{g}_{\mathrm{i}}\right|^{2}\right)^{2}\right\}^{2}=\mathrm{K}_{0}
$$

The inequality of the third and fourth terms in (31) holds with equality if and only if

$$
\sum_{i \neq k}\left|g_{i}\right|^{2}\left|g_{k}\right|^{2}=0
$$

From $\sum_{i=1}^{n}\left|g_{i}\right|^{2}=1$ and (32), we have

$$
\begin{array}{ll}
\left|g_{i_{0}}\right|=1 & \text { for some } i_{0} \in I_{0} \\
\left|g_{i}\right|=0 & \text { for any } i \neq i_{0}
\end{array}
$$

Here, $I_{0}$ is the subset of natural numbers less than or equal to $\mathrm{n}$ defined by $\mathrm{I}_{0}=\left\{\mathrm{i} \in\{1, \ldots, \mathrm{n}\} \mid \mathrm{Ks}_{\mathrm{i}}=\mathrm{K}_{0}\right\}$. Therefore, we have $\mathrm{Ky}=\mathrm{K}_{0}$ when $\mathrm{Q}_{\mathrm{B}}$ is maximized under $\mathrm{gg}^{* \mathrm{~T}}=1$ $\left(\sum_{i=1}^{n}\left|g_{i}\right|^{2}=1\right)$. 